\title{
Blind sampling is superior to anoscope guided sampling for screening for anal intraepithelial neoplasia
}

\author{
C M Vajdic, J S Anderson, R J Hillman, G Medley, A E Grulich
}

Sex Transm Infect 2005;81:415-418. doi: 10.1136/sti.2004.014407

See end of article for authors' affiliations .....................

Correspondence to: Claire Vajdic, National Centre in HIV Epidemiology and Clinical Research, University of New South Wales, Level 2/376 Victoria Street, Sydney, NSW, 2010, Australia; cvajdic@nchecr. unsw.edu.au

Accepted for publication 24 February 2005

\begin{abstract}
Objectives: Anal cytology smears are either collected "blind" (swab inserted $4 \mathrm{~cm}$ into anal canal and rotated) or guided through an anoscope (transformation zone visualised and then sampled). We compared these smear techniques with respect to sample quality and patient acceptability.

Methods: Using a paired, random sequence clinical trial, 151 homosexual men ( $n=95$ HIV positive) underwent both smear techniques at a single visit; smear order was randomised and specimens were read blind. Both techniques utilised a Dacron swab, with water lubrication. Cytological specimens were prepared using a liquid based collection method (ThinPrep). The outcome measures were cytological specimen adequacy, cytological classification, presence of rectal columnar, squamous and metaplastic cells, contamination, patient comfort and acceptability, and volume of fluid that remained after the ThinPrep procedure.

Results: Regardless of smear order, guided smears were less likely to detect higher grade abnormalities than blind smears (15 v 27 cases, $p=0.001)$. Controlling for smear order, guided smears were more likely to be assessed as "unsatisfactory" for cytological assessment (OR 6.93,95\% Cl 1.92 to 24.94), and contain fewer squamous (OR $0.20,95 \% \mathrm{Cl} 0.04$ to 0.94 ) and metaplastic cells (OR $0.12,95 \% \mathrm{Cl} 0.03$ to 0.54) than blind smears; there were no other statistically significant differences between techniques. Regardless of smear technique, first performed smears were more likely to detect a higher grade abnormality than second performed smears ( $23 v$ eight cases, $\mathrm{p}<0.001)$.

Conclusions: Blind cytology smears are superior to anoscope guided smears for screening for anal neoplasia in homosexual men.
\end{abstract}

$\mathrm{t}$ is established that homosexual men have high rates of anal cancer $^{1}$ and the presumed precursor lesion, anal intraepithelial neoplasia (AIN). ${ }^{2-5}$ These associations have led some to propose the screening of homosexual men by anal cytology smear, ${ }^{67}$ although the harms and benefits of screening are not well understood.

Past studies of AIN have used one of two techniques for the collection of anal cells, the "blind" method" ${ }^{28-16}$ and the anoscope guided method. ${ }^{45-21}$ Anoscope guided sampling allows directed sampling from the ano-rectal transformation zone, the area of the anal canal where squamous carcinoma and its precursors most frequently develop. ${ }^{12}$ However, "blind" or non-guided sampling is the most widely used technique, typically physician collected rather than self collected..$^{22}$ There is an extensive literature describing comparisons between blind "self sampling" and speculum directed cervical smears, ${ }^{23}$ but there has been little evaluation of physician collected anal smears. Unlike cervical smears, faecal contamination is an issue of concern with anal smears, with a resultant relatively high smear inadequacy rate. ${ }^{13} 1624$ Furthermore, given the associations between anal human papillomavirus (HPV) infection and both anal cancer and AIN, ${ }^{5}{ }^{1825}$ the sampling technique must provide adequate cellularity for both cytology and ancillary tests such as HPV detection. We conducted a direct comparison of the two anal sampling techniques using a random sequence, paired design clinical trial.

\section{METHODS}

\section{Study design}

Two experienced clinicians, trained in the collection of anal cytology smears and anoscopy, enrolled participants and performed the anal smears. The anal canal of each participant was sampled using each technique at the same visit. The order in which the techniques were performed was randomised because of the unknown extent of any order effects. Smear order was pre-assigned in a sealed envelope that was opened only after informed verbal consent was established. Written consent was then obtained, and each participant completed a brief questionnaire about the recent use of their anus, and relevant medical history.

For both smears a Dacron swab moistened with water was rotated against the canal wall for 1 minute before being removed from the anal canal, shaken vigorously in liquid fixative PreservCyt (Cytyc Corporation) transport medium, and then discarded. During the "blind" smear the swab was also rotated against the canal wall during removal. For the anoscope guided smear a water lubricated clear plastic disposable anoscope was inserted $3-5 \mathrm{~cm}$ into the anal canal and adjusted with the aid of an external light source to reveal the transformation zone before sampling. During withdrawal of the anoscope the distal anal canal was inspected for warts or other abnormality and areas of interest were sampled. After smearing, participants rated the comfort and acceptability of each technique.

A cytologist processed the samples using the ThinPrep system (Cytyc Corporation) and then an experienced pathologist performed a conventional cytological assessment of the stained diagnostic cellular material. Anal cytology was classified using the Bethesda criteria for cervical cytology, with cross reference to the Australian Modified Bethesda

\footnotetext{
Abbreviations: AIN, anal intraepithelial neoplasia; ASCUS, atypical squamous cells of undetermined significance; HPV, human papillomavirus; HGSIL, high grade squamous intraepithelial lesion LGSIL, low grade squamous intraepithelial lesion; MSM, men who have
} sex with men 
Table 1 Characteristics* of the 151 homosexual male participants

\begin{tabular}{|c|c|}
\hline Age (years) & 45 (11) (19-76) \\
\hline HIV positive & $95(64 \%)$ \\
\hline Lowest CD4 count† (cells $\times 10 /{ }^{6}$ ) & $249(186)(0-860)$ \\
\hline Last CD4 count† (cells $\times 10 / 6$ ) & $580(267)(120-1462)$ \\
\hline Last plasma HIV-RNA load (copies/ml) & $13049(30840)(50-122000)$ \\
\hline Previous medical treatment of anus/canal & $61(43 \%)$ \\
\hline History of anal or genital wartsł & $72(50 \%)$ \\
\hline Current anal or genital warts§ & $24(18 \%)$ \\
\hline Last bowel movement (hours) & $6(7)(0-48)$ \\
\hline \multicolumn{2}{|l|}{ Anal cytology by worst case smear } \\
\hline Inadequate samples & $8(5 \%)$ \\
\hline Negative & $49(32 \%)$ \\
\hline ASCUS & $24(16 \%)$ \\
\hline LGSIL (HPV, AINI) & $41(27 \%)$ \\
\hline HGSIL (AINII, AINIII) & $29(19 \%)$ \\
\hline $\begin{array}{l}\text { ASCUS, atypical squamous cells of undeter } \\
\text { LGSIL, low grade squamous intraepithelial } \\
\text { *Data are mean (SD) (range) or proportion } \\
\text { †For } 95 \text { HIV positive participants. } \\
\text { †Available for } 143 \text { participants. } \\
\text { §Available for } 134 \text { participants. }\end{array}$ & IGSIL, high grade squamous intraepithelial lesion \\
\hline
\end{tabular}

System. The cytologist and pathologist were blind to sample order and technique.

The human research ethics committee at each participating institution approved the study.

\section{Study population}

Men who have sex with men (MSM) were recruited from a primary care clinic specialising in homosexual men's health and a community based HIV testing and treatment centre. Consecutively presenting and referred MSM at least 18 years of age were approached. Men with a bleeding condition, and those taking anticoagulants (excluding aspirin/acetylsalicylic acid), or with symptomatic anal disease, the severity or location of which would prevent taking of the smears, were ineligible.

\section{Outcome measures}

Smear specimens were compared with respect to adequacy for diagnostic cytology, contamination, the cell types present, the cytological classification, the sample volume remaining after the ThinPrep procedures, and participant comfort and acceptance.

\section{Statistical analyses}

The outcomes were separately examined by smear order and sampling technique using Stata (StataCorp, TX, USA). The $t$ test was used for sample volume. For the categorical outcome variables, the extent of any effect by smear order and smear technique were separately assessed by comparing all categories of outcome data for paired samples. Where necessary, the categorical data were then dichotomised and paired samples were compared using McNemar's $\chi^{2}$ test. Conditional fixed effects logistic regression was then used to estimate the independent effects of smear order and technique, controlling for the other. In the regression analysis, smear adequacy was examined for all participants, and the remaining outcome variables were examined only for those participants with two adequate smears $(n=120)$.

\section{RESULTS}

\section{Participant characteristics}

The characteristics of the 151 MSM enrolled in the study are outlined in table 1. Seventy eight men underwent a "blind" smear followed by an anoscope guided smear; smear order was reversed for the remaining 73 participants. An anal cytological abnormality was detected in $62 \%$ of participants. HIV positive men were significantly more likely to have a cytology detected abnormality than HIV negative men (71\% $\mathrm{v}$ $49 \%, \mathrm{p}=0.03$ ).

\section{Cytology outcomes}

Regardless of smear order, and ignoring cases with identical results for both smears, anoscope guided smears were more likely to be rated as inadequate for cytological assessment (20 $v$ three cases, $\mathrm{p}=0.0004$ ), less likely to detect a higher grade cytological abnormality ( $15 \vee 27$ cases, $\mathrm{p}=0.001$ ), less likely to contain a greater number of squamous cells ( $36 v 48$ cases, $\mathrm{p}=0.02)$, and they were less likely to contain metaplastic cells (two $v 16$ cases, $\mathrm{p}=0.001$ ), than "blind" smears.

Overall, "blind" smears "missed" one case of ASCUS, seven cases of LSIL and seven cases of HGSIL. Anoscope guided smears "missed" 10 ASCUS, nine LSIL, and eight HGSIL.

Regardless of smear technique, and ignoring cases with identical results for both smears, first performed smears were more likely to detect a higher grade cytological abnormality (23 $v$ eight cases, $\mathrm{p}<0.001$ ) and they were more likely to contain a greater number of squamous cells (66 $v 18$ cases, $\mathrm{p}<0.0001$ ), than second performed smears.

Table 2 shows the independent effects of smear order and smear technique for the dichotomous outcome variables. After controlling for smear order, "blind" smears were significantly more likely to be rated as adequate for cytological assessment compared to anoscope guided smears, and they also contained significantly more squamous and metaplastic cells. There were no significant differences between first and second performed smears, after controlling for smear technique.

For satisfactory smears, there was no correlation between the presence of rectal glandular cells and the detection of anal dysplasia. Regardless of smear order or technique, anal dysplasia was detected in $71 \%$ of smears without any rectal cells and $64 \%$ of smears with some rectal cells.

\section{Volume of fluid after ThinPrep analysis}

There was no difference between first and second performed smears, or between "blind" and anoscope guided smears, in the volume of fluid remaining after ThinPrep preparation.

\section{Comfort and acceptance and clinical findings}

There were no significant differences in the reported comfort or acceptance of the two techniques, and both were well tolerated (table 3). Bleeding after the smear was more common with the anoscope than without ( $9 \% \vee 4 \%)$. The 
Table 2 Odds ratios for the independent effects of anal smear order and smear technique for dichotomous cytological outcome variables

\begin{tabular}{|c|c|c|}
\hline & $\begin{array}{l}\text { "Blind" compared } \\
\text { to guided smears" }\end{array}$ & $\begin{array}{l}\text { Second compared } \\
\text { to first smears* }\end{array}$ \\
\hline $\begin{array}{l}\text { Smear cytologically adequate } \dagger \\
\text { Positive cytological diagnosis } \ddagger \S \\
\text { No contamination of smear } \ddagger \\
\text { No squamous cells detected } \ddagger \\
\text { No rectal cells detected } \ddagger \\
\text { No metaplastic cells detected } \ddagger\end{array}$ & $\begin{array}{l}6.93(1.92 \text { to } 24.94) \\
1.67(0.60 \text { to } 4.66) \\
1.51(0.69 \text { to } 3.32) \\
0.20(0.04 \text { to } 0.94) \\
0.64(0.32 \text { to } 1.28) \\
0.12(0.03 \text { to } 0.54)\end{array}$ & $\begin{array}{l}0.87(0.24 \text { to } 3.12) \\
0.48(0.17 \text { to } 1.33) \\
0.76(0.34 \text { to } 1.67) \\
0.82(0.18 \text { to } 3.75) \\
1.28(0.64 \text { to } 2.56) \\
\text { NA }\end{array}$ \\
\hline \multicolumn{3}{|c|}{$\begin{array}{l}\text { *Odds ratio }(95 \% \mathrm{Cl}) \text {. } \\
\text { †Effect examined for all } 151 \text { participants. } \\
\text { tEffect examined only for } 120 \text { participants with two adequate smears. } \\
\S \text { Smears with a diagnosis of ASCUS, LGSIL or HGSIL were classified as positive } \\
\text { ๆOR and } 95 \% \mathrm{Cl} \text { could not be calculated because of a zero cell. }\end{array}$} \\
\hline
\end{tabular}

transformation zone could not be located during the anoscope guided technique for $27 \%$ of participants; however, visualisation of the zone was unrelated to specimen adequacy.

\section{DISCUSSION}

We found that the "blind" smear is superior to the anoscope guided smear for sampling anal cells from MSM. Compared to anoscope guided smears, "blind" smears were significantly more likely to be rated as adequate for cytological assessment, and significantly more likely to contain squamous and metaplastic cells. This finding suggests that use of the anoscope may hinder anal cell collection, depending on its location in the canal, because access to the squamous epithelium distal to the transformation zone may be prevented. It is also possible that the insertion of the anoscope, with only water as a lubricant, may have caused some desquamation and contributed to the lower cellular yields. When analysed by detailed grades we also found that second taken smears were inferior at detecting higher grade abnormalities. This finding has potential implications for studies requiring multiple anal samples at a single visit.

The strengths of the study include the pre-assigned randomisation of smear order, the collection of both smears at the same visit, the blinded assessment of study outcomes by a single pathologist, and the use of identical processing procedures for both samples. However, we lost some ability to discriminate between paired smears because of the requirement for the use of dichotomous outcome variables for the statistical analysis of paired samples. This is particularly important for the cytological classification as there are clinically important differences between ASCUS, LGSIL, and HGSIL that we could not fully examine.

We chose a high risk population in order to detect a high prevalence of anal dysplasia and enhance our ability to detect statistically significant differences between smears. However, it is unclear whether our findings are generalisable to other high risk populations or populations with low disease prevalence.

There has been no previous direct comparison of "blind" and anoscope guided smears. A comparison of smear adequacy rates and dysplasia detection rates reported by separate studies using either smear is not meaningful because of between study variation in the criteria used to define a cytologically adequate sample, the sampling device (dry or moistened swab, wooden spatula, or brush), the duration of sampling, and the sample processing (conventional or liquid based).

The poorer performance of the anoscope guided smears in this study cannot be attributed to interference to the ThinPrep sample preparation system from lubricant applied to the anoscope, as only water was used. The most likely explanation is undersampling of the mucosa between the transformation zone and anal verge during removal of the anoscope.

Our study did confirm that in satisfactory smears the absence of rectal glandular cells was not correlated with the detection of anal neoplasia. ${ }^{13}$ This has also shown to be true for cervical screening specimens without endocervical glandular cells. ${ }^{26}$

There have been no previous studies of the effects of sequential sampling of the anal canal. Our data suggest an order effect when sampling from the anal canal, lending support to the current practice of taking an anal cytology smear before an anal swab for microbiological or molecular assessment. This finding also has potential implications for cervical screening and the use of two consecutive smears.

In conclusion, we found that the "blind" anal smear is superior to the anoscope guided anal smear for screening MSM for anal neoplasia. Our findings support the continued use of a cytology smear technique that is simple, quick, and relatively inexpensive to perform, and readily accepted by patients. However, the use of anoscopy may be clinically indicated by symptomatology and so should be considered after sampling for anal cytology in such cases.

Table 3 Mean comfort and acceptance ratings for the blind and anoscope guided anal smear techniques

\begin{tabular}{|c|c|c|c|}
\hline \multirow[b]{2}{*}{ Description of procedure } & \multicolumn{2}{|c|}{ Mean (range)* rating } & \multirow[b]{2}{*}{ p Value } \\
\hline & $\begin{array}{l}\text { Blind } \\
(n=150)\end{array}$ & $\begin{array}{l}\text { Anoscope guided } \\
(n=149)\end{array}$ & \\
\hline It was painful & $2.0(1-5)$ & $2.1(1-5)$ & 0.37 \\
\hline It was uncomfortable & $2.6(1-5)$ & $2.8(1-5)$ & 0.13 \\
\hline I felt at ease & $3.9(1-5)$ & $3.8(1-5)$ & 0.37 \\
\hline I am prepared to have the procedure again & $4.2(1-5)$ & $4.2(1-5)$ & 1.00 \\
\hline
\end{tabular}




\section{Key messages}

- Blind smears are cytologically superior to anoscope guided smears for screening for anal intraepithelial neoplasia in homosexual men

- A clinic based sample of homosexual men reported no difference in comfort between blind and anoscope guided anal smears

- Second taken anal smears are inferior at detecting higher grade anal abnormalities

\section{ACKNOWLEDGEMENTS}

The authors are grateful to Jeff Jin for performing the data entry. The National Centre in HIV Epidemiology and Clinical Research is funded by the Australian Government Department of Health and Ageing, and is affiliated with the Faculty of Medicine, The University of New South Wales. Claire Vajdic has a postdoctoral research fellowship from the National Health and Medical Research Council.

\section{CONTRIBUTORS}

GM, CMV, and AEG conceived and designed the study; CMV coordinated the study, performed the data analysis, and wrote the initial draft; JSA and RJH recruited participants, performed the clinical procedures, provided demographic and behavioural data, and made comments on drafts; GM performed the cytopathology and made comments on drafts; AEG made comments on drafts.

\section{Authors' affiliations}

C M Vajdic, J S Anderson, A E Grulich, National Centre in HIV Epidemiology and Clinical Research, University of New South Wales, Sydney, Australia

J S Anderson, Carlton Clinic, Melbourne, Australia

R J Hillman, Sexually Transmitted Infections Research Centre, Westmead Hospital, Sydney, Australia, and, Albion Street Clinic, Sydney, Australia G Medley, Dorevitch Pathology, Mayne Health, Melbourne, Australia

Support: Cytyc Corporation Australia provided ThinPrep vials containing PreservCyt transport medium and ThinPrep Filters.

Competing interests: The authors have no possible conflicts of interest, including financial, consultant, institutional, or other relationships that might lead to bias or conflict of interest.

\section{REFERENCES}

1 Daling JR, Weiss NS, Hislop TG, et al. Sexual practices, sexually transmitted diseases, and the incidence of anal cancer. N Engl J Med 1987;317:973-7.

2 Palefsky JM, Holly EA, Ralston ML, et al. Anal squamous intra-epithelial lesions in HIV-positive and HIV-negative homosexual and bisexual men: prevalence and risk factors. J AIDS Hum Retrovirol 1998;17:320-6.

3 Palefsky JM, Gonzales J, Greenblatt RM, et al. Anal intraepithelial neoplasia and anal papillomavirus infection among homosexual males with group IV HIV disease. JAMA 1990;263:2911-16.
4 Lacey HB, Wilson GE, Tilston P, et al. A study of anal intraepithelial neoplasia in HIV positive homosexual men. Sex Transm Infect 1999;75:172-7.

5 Carter PS, De Ruiter A, Whatrup C, et al. HIV infection and genital warts as risk factors for anal intraepithelial neoplasia in homosexual men. $\mathrm{Br} J$ Surg 1995:82:473-4.

6 Palefsky JM. Anal HPV infection and anal cancer in HIV-positive individuals: an emerging problem. AIDS 1994;8:283-95.

7 Goldie SJ, Kuntz KM, Weinstein MC, et al. Cost effectiveness of screening for anal SIL and anal cancer in HIV-negative homosexual and bisexual men. Am J Med 2000;108:634-41.

8 Caussy D, Goedert JJ, Palefsky J, et al. Interaction of human immunodeficiency and papilloma viruses: association with anal epithelial abnormality in homosexual men. Int J Cancer 1990;46:214-19.

9 Melbye M, Palefsky J, Gonzales J, ef al. Immune status as a determinant of human papillomavirus detection and its association with anal epithelial abnormalities. Int J Cancer 1990;46:203-6.

10 Surawicz CM, Kirby P, Critchlow C, et al. Anal dysplasia in homosexual men: role of anoscopy and biopsy. Gastroenterology 1993;105:658-66.

11 Kiviat NB, Critchlow CW, Holmes KK, et al. Association of anal dysplasia and human papillomavirus with immunosuppression and HIV infection among homosexual men. AIDS 1993;7:43-9.

12 De Ruiter A, Carter P, Katz DR, et al. A comparison between cytology and histology to detect anal intraepithelial neoplasia. Genitourin Med 1994;70:22-5.

13 Sherman ME, Friedman HB, Busseniers AE, et al. Cytologic diagnosis of anal intraepithelial neoplasia using smears and cytyc thin-preps. Mod Pathol 1995:8:270-4.

14 Critchlow CW, Surawicz CM, Holmes KK, et al. Prospective study of high grade anal squamous intraepithelial neoplasia in a cohort of homosexual men: influence of HIV infection, immunosuppression and human papillomavirus infection. AIDS 1995:9:1255-62.

15 Friedman HB, Saah AJ, Sherman MA, et al. Human papillomavirus, anal squamous intraepithelial lesions, and human immunodeficiency virus in a cohort of gay men. J Infect Dis 1998; 178:45-52

16 Scholefield JH, Johnson J, Hitchcock A, et al. Guidelines for anal cytology-to make cytological diagnosis and follow up much more reliable. Cytopathology 1998;9:15-22.

17 Medley G. Anal smear test to diagnose occult anorectal infection with human papillomavirus in men. Br J Vener Dis 1984;60:205.

18 Frazer IH, Medley G, Crapper RM, et al. Association between anorectal dysplasia, human papillomavirus and human immunodeficiency virus in homosexual men. Lancet, 1986; ii, 657-60.

19 Haye KR, Maiti H, Stanbridge CM. Cytological screening to detect subclinical anal human papillomavirus (HPV) infection in homosexual men attending genitourinary medicine clinic. Genitourin Med 1988;64:378-82.

20 Law CLH, Qassim M, Thompson CH, et al. Factors associated with clinical and subclinical anal human papillomavirus infection in homosexual men. Genitourin Med 1991;67:92-8.

21 Velasco J, Palacio V, Vazquez S, et al. Diagnostic accuracy of the cytologic diagnosis of anal human papillomavirus infection compared with DNA hybridization studies. Sex Transm Dis 1993;20:147-51

22 Cranston R, Darragh T, Holly E, et al. Self-collected versus clinician-collected anal cytology specimens to diagnose anal intraepithelial neoplasia in HIVpositive men. J Acquir Immune Defic Syndr 2004;36:915-20.

23 Garcia F, Barker B, Santos S, et al. Cross-sectional study of patient- and physician-collected cervical cytology and human papillomavirus. Obstet Gynecol 2003;102:266-72.

24 Darragh TM, Jay N, Tupkelewicz BA, et al. Comparison of conventional cytologic smears and ThinPrep preparations from the anal canal. Acta Cytol 1997; 41:1167-70.

25 Palefsky JM, Holly EA, Gonzales J, et al. Detection of human papillomavirus DNA in anal intraepithelial neoplasia and anal cancer. Cancer Res 1991;51:1014-19.

26 Baer A, Kiviat N, Kulasingam S, et al. Liquid-based Papanicolaou smears without a transformation zone component: should clinicians worry? Obstet Gynecol 2002;99:1053-9 